\title{
Structural and Thermodynamic Characteristics of the Exosite Binding Pocket on the Human BACE1: A Molecular Modeling Approach
}

\author{
Lucas J. Gutierrez, ${ }^{\dagger, \dagger}$ Ricardo D. Enriz, ${ }^{\dagger, \dagger}$ and Héctor A. Baldoni*, ${ }^{*, \$}$ \\ Área de Química General e Inorgánica, Universidad Nacional de San Luis (UNSL), Chacabuco 917, \\ 5700 San Luis, Argentina, Instituto Multidisciplinario de Investigaciones Biológicas de San Luis (UNSL, \\ CONICET), Ejercito de Los Andes 950, 5700 San Luis, Argentina, and Instituto de Matemática Aplicada San \\ Luis (UNSL, CONICET), Ejercito de Los Andes 950, 5700 San Luis, Argentina
}

Received: May 31, 2010; Revised Manuscript Received: July 29, 2010

\begin{abstract}
We report a molecular modeling study aimed to locate and provide the full structural characteristics of the exosite binding site of the BACE1. A three-step procedure was followed. In the first stage, we performed blind docking studies on the whole target surface. In a second stage, the mode of binding was further refined by molecular dynamics (MD) simulation. Finally, binding free energy calculations, through the MM-PBSA protocol, were carried out to gain insight into the stability and thermodynamics of the inhibitor located at the selected binding pockets. Twelve binding pockets were identified on the surface of BACE1 by blind docking studies. The calculations of binding free energies for the 12 complexes show that van der Waals interactions dominate the mode of binding of these complexes. The best ranked complex shows that residues Glu255Pro258, Phe261, Gly264-Ala272, Asp311-Ala313, Ser315, and Asp317-Tyr320 are located within 6 A from the INH located at the exosite. The hydrogen bonds formed between the INH peptide, residues Tyr1, Tyr3, and Leu7 with the BACE1 residues Leu267, Cys269, Trp270, Asp311, and Asp 317 can strengthen the binding of the BACE1-INH complex.
\end{abstract}

\section{Introduction}

Alzheimer disease (AD) is a degenerative brain syndrome first described by Alois Alzheimer in 1906, which affects more than 37 million people worldwide. ${ }^{1}$ Although the etiology remains enigmatic, $\mathrm{AD}$ appears to be brought about by genetic and nongenetic factors. There are two main theories in relation to $\mathrm{AD}$ treatment. The "cholinergic hypothesis" relates the neurodegeneration to the loss of cholinergic neurotransmission, while the current "amyloid hypothesis" correlates the increased $\mathrm{A} \beta$ production or reduced $\mathrm{A} \beta$ clearance to the formation of $\mathrm{A} \beta$ deposits, leading to the progression of the $\mathrm{AD}^{.2-6} \mathrm{~A} \beta$ is generated in vivo through proteolytic cleavage of the membraneanchored $\beta$-amyloid precursor (APP) by the $\beta$-site amyloid cleaving enzyme (BACE1) (also called $\beta$-secretase, memapsin 2, or ASP-2). ${ }^{7-16}$

BACE1 has long been regarded as a therapeutic target for $\mathrm{AD}$ in the development of inhibitor drugs for reduction of $\mathrm{A} \beta$. The cloning and identification of BACE1, first reported in $1999,{ }^{17-21}$ invigorated research on both the protease and its inhibitor drugs in many laboratories around the world. ${ }^{22-27}$ The bilobal structure of BACE1 has the conserved general folding of the aspartic proteases superfamily and more precisely the pepsin subfamily. ${ }^{17-20}$ The crystal structures of BACE1 confirm that the active site is a long cleft for the substrate recognition with two catalytic aspartic residues. ${ }^{28,29}$ Kinetic and specificity studies showed that BACE1 interacts with approximately 11

* To whom correspondence should be addressed. Phone: $+54-2652$ 43789, ext 157. Fax: +54-2652-422803. E-mail: hbaldoni@unsl.edu.ar.

† Área de Química General e Inorgánica, Universidad Nacional de San Luis (UNSL).

${ }^{\ddagger}$ Instituto Multidisciplinario de Investigaciones Biológicas de San Luis (UNSL, CONICET)

${ }^{\S}$ Instituto de Matemática Aplicada San Luis (UNSL, CONICET). substrate residues, with affinity to many hydrophobic residues but somewhat broad in specificity. ${ }^{30,31}$

In addition to the active site, some proteolytic enzymes contain additional binding pockets, termed exosites, which engage substrates at locations distal to the active site. ${ }^{32-36}$ These binding pockets can contribute significantly to the stabilization of the enzyme-substrate binary complex by providing important structural determinants of interaction. Additionally, exosites on some proteolytic enzymes can act as allosteric regulators of the enzyme activity through conformational changes to the active site, in order to cause an augmentation or diminution of the enzyme's catalytic reactivity. In some cases, molecules bind to an exosite of a protease, proving to be effective modulators of enzymatic activity. ${ }^{34,35}$ Hence, exosites represent an alternative target for regulatory ligands binding to proteolytic enzymes. Because the exosites are structurally distinct from the active sites of these enzymes, the nature of the molecules that bind to the exosites may be different from that of active-site-directed inhibitors. Therefore, it is possible that in some cases the exosite could provide a more pharmacologically tractable target for small molecule interactions than does the active site of the enzyme. Finally, the structural diversity of exosites among related enzymes may be greater than that of the enzyme active sites, thus potentially providing a means for the development of highly selective modulators.

While exosites were reported for serine and cysteine proteases, few examples of exosites have been reported for aspartyl proteases ${ }^{36,37}$ Kornacker et al. reported the discovery of an exosite within the catalytic domain of the human BACE1 that binds small peptides in a manner that is unaffected by active site ligand occupancy. ${ }^{37,38}$ Peptides that bind in this exosite inhibit the ability of BACE1 to hydrolyze its natural protein substrate, APP. The size of these peptides and the nature of the amino acids required for binding to this pocket suggest that it 
may be possible to inhibit the catalytic activity of BACE1 by binding small, drug-like molecules to this exosite. ${ }^{37,38}$ It is clear, therefore, that the knowledge of the structural details of this exosite is of paramount importance for the design and development of new inhibitors.

Despite the importance of this regulatory mechanism, there is in fact only limited and partial structural information of this exosite. ${ }^{37,38}$ Thus, although the crystal structure of the enzyme-substrate-inhibitor ternary complex has been determined, ${ }^{38}$ to our knowledge, it is not in the public domain. In the present work, we present a molecular modeling study aimed to locate and provide the full structural characteristics of the exosite binding pocket of BACE1. We performed blind docking studies, followed by molecular dynamics (MD) simulation, in order to refine the mode of binding. Finally, binding free energy calculations were carried out to gain insight into the structure, binding mode, stability, and thermodynamics of the inhibitor located at the BACE1 exosite binding pocket.

\section{Methods}

Enzyme Substrate Model (ES). Coordinates of BACE1 determined at $2.1 \AA$ resolution in complex with the peptidomimetic substrate OM00-3 (Glu-Leu-Asp-Leu- $\left(\mathrm{CH}(\mathrm{OH})-\mathrm{CH}_{2}\right)$ Ala-Val-Glu-Phe, where $\left(-\mathrm{CH}(\mathrm{OH})-\mathrm{CH}_{2}-\right)$ depicts the hydroxyethylene isostere of the peptide bond) were downloaded from the PDB database ${ }^{39}$ (entry $1 \mathrm{M} 4 \mathrm{H}^{29}$ ) and used as a structural template.

Simulations were performed in the presence of the peptidomimetic substrate modeled as an all-trans Glu-Leu-Asp-LeuAla-Val-Glu-Phe peptide. The B chain and all water molecules were removed from the PDB file. Particular attention was given to the ionization state of the active site, which contained the aspartyl dyad (Asp32/Asp228). At optimal $\mathrm{pH}$ for enzymatic activity $(\sim 3.5-4.5),{ }^{40}$ the aspartyl dyad is most probably monoprotonated in the uncomplexed enzyme as well as in the complex with the substrate. In this study, the ionizable residues were modeled in the protonation state corresponding to $\mathrm{pH} 4.5$ obtained using the $\mathrm{H}++$ software. ${ }^{41-43}$ Asp32 was protonated on the basis of the computed $\mathrm{p} K_{\mathrm{a}}$ on the $1 \mathrm{M} 4 \mathrm{H} \mathrm{X}$-ray structure. The protonation of Asp32 was also suggested by a previous MD and docking study. ${ }^{44}$ Although a recent quantum-chemical study suggests dideprotonated and monoprotonated states for the free and complexed forms of BACE1, respectively, ${ }^{45}$ dideprotonation is in contradiction with the accepted reaction mechanism of pepsin-like enzymes, ${ }^{46,47}$ which requires that one of the aspartic residues be protonated.

Inhibitor Peptide (INH). The peptide Ac-Tyr-Pro-Tyr-PheIle-Pro-Leu- $\mathrm{NH}_{2}$ (INH), initially identified from a combinatorial phage peptide library, ${ }^{37}$ was selected to model the inhibitor. This INH represents a minimal peptide that retains good binding affinity to BACE and binds the exosite pocket with $K_{\mathrm{d}}=1.2$ $\mu \mathrm{M},{ }^{38}$ forming a ternary complex with the ES species in a noncompetitive way with respect to the substrate. ${ }^{37,38}$ Therefore, this peptide becomes an excellent candidate to carry out the "blind docking" analysis.

Blind Docking. Molecular docking ${ }^{48,49}$ as implemented in the AutoDock program ${ }^{50}$ was performed. The docking of the INH was carried out on the entire protein surface without prior specification of the binding site ("blind docking"). ${ }^{51-56}$ Starting from a snapshot taken at $10 \mathrm{~ns}$ of a previously equilibrated ES system (data not shown), following the same MD conditions listed below (see Binding Mode in the Methods section), AutoDock 3.0.5 was used to dock the INH to the ES surface using a Lamarckian genetic algorithm with pseudo-Solis and Wets local search. ${ }^{50}$

The following parameters were used: the initial population of trial ligands was constituted by 250 individuals; the maximum number of generations was set to $2.7 \times 10^{4}$. The maximum number of energy evaluations was $10.0 \times 10^{6}$. All other run parameters were maintained at their default setting. The $3 \mathrm{D}$ affinity map was a cube with $126 \times 126 \times 126$ points separated by $0.6 \AA$ and centered at the ES complex. Polar hydrogen atoms and charges were added to the ES and INH models using AutoDock. ${ }^{50}$ The exact same preparation and docking processes were applied to eight different AutoDock jobs starting each one with the fully flexible ligand from each corner of the affinity cube. The docking procedure was applied to the whole ES surface, without imposing any binding site. The resulting docked conformations were clustered into families by the backbone rmsd. The lowest docking-energy conformation of each family was considered the most favorable orientation. ${ }^{57}$

Binding Mode. After the blind docking process, the coordinates of the lowest energy structure of each ES-INH ternary complex were extracted and subjected to molecular dynamics (MD). All MD simulations were done with the Amber package ${ }^{58}$ using the Duan et al. force field. ${ }^{59}$ The solvent effects were taken into account through the generalized Born model developed by Onufriev et al. ${ }^{60,61}$ The surface area was included in the solvation term and has been computed using the LCPO model. ${ }^{62} \mathrm{~A}$ monovalent electrostatic ion screening of $0.2 \mathrm{M}$ was used. ${ }^{63}$ The SHAKE algorithm ${ }^{64}$ was employed to constrain all hydrogen atoms, leading to a $2.0 \mathrm{fs}$ time increment. The temperature was maintained using the Langevin thermostat ${ }^{65,66}$ with a collision frequency of $2.5 \mathrm{ps}^{-1}$. A $99 \AA$ cutoff was set to the long-range nonbonded interactions. The geometries were first energyoptimized to remove possible bumps. Conjugate gradient energy minimizations were performed three times using positional restraints to all $\mathrm{C} \alpha$ atoms with 500,100 , and $0 \mathrm{kcal} /(\mathrm{mol} \AA)$ force constants, in sequence. Further, the unrestrained system was heated from 10 to $298 \mathrm{~K}$ over $25 \mathrm{ps}$. Finally, $2.0 \mathrm{~ns}$ production runs were generated by MD simulations, collecting snapshots every 1 ps. For each simulation, the analyses were done over the last $1.0 \mathrm{~ns}$.

Binding Energy Calculations. The MM-PBSA protocol was applied to each MD trajectory in order to calculate the relative binding energies of the ES-INH ternary complexes. The MMPBSA method was used in a hierarchical strategy and the details of this method have been presented elsewhere. ${ }^{67}$ This protocol was applied to 100 equidistant snapshots extracted from the last $1.0 \mathrm{~ns}$ of simulation and was used within the one-trajectory approximation. Briefly, the binding affinity for a complex corresponds to the free energy of association written as

$$
\Delta G_{\text {bind }}=G_{\text {complex }}-\left(G_{\text {receptor }}-G_{\text {ligand }}\right)
$$

while the relative affinities for a ligand to different binding pocket can be calculated as

$$
\Delta \Delta G_{\mathrm{bind}(1 \rightarrow 2)}=\Delta G_{\mathrm{bind}(2)}-\Delta G_{\mathrm{bind}(1)}
$$

In the MM-PBSA protocol, the binding affinity in eq 1 is typically calculated using

$$
\Delta G=\Delta E_{\mathrm{MM}}+\Delta G_{\mathrm{solv}}-T \Delta S_{\text {solute }}
$$


TABLE 1: Parameters for the Binding Sites Identified by "Blind Docking"

\begin{tabular}{|c|c|c|c|c|c|c|c|}
\hline \multirow[b]{2}{*}{ complex } & \multirow[b]{2}{*}{$N^{a}$} & \multicolumn{3}{|c|}{$\mathrm{SASA}^{b}$} & \multirow[b]{2}{*}{ volume $^{c}$} & \multirow[b]{2}{*}{$\Delta G_{\text {bind }}{ }^{d}$} & \multirow[b]{2}{*}{$\Delta \Delta G_{\text {bind }}^{e}$} \\
\hline & & total & apolar & polar & & & \\
\hline $\mathrm{C} 1$ & 15 & 473.45 & 430.50 & 42.95 & 222.94 & -11.64 & 0.00 \\
\hline C3 & 35 & 584.35 & 527.25 & 57.15 & 233.72 & -10.61 & 1.03 \\
\hline $\mathrm{C} 4$ & 35 & 574.20 & 527.40 & 46.80 & 413.21 & -10.47 & 1.17 \\
\hline C5 & 29 & 575.25 & 498.55 & 76.70 & 332.50 & -10.37 & 1.27 \\
\hline C6 & 10 & 522.40 & 479.15 & 43.25 & 226.02 & -10.12 & 1.52 \\
\hline C8 & 14 & 468.70 & 427.65 & 41.05 & 269.80 & -9.94 & 1.70 \\
\hline C9 & 45 & 512.30 & 458.70 & 53.60 & 196.03 & -9.93 & 1.71 \\
\hline $\mathrm{C} 10$ & 12 & 391.60 & 353.20 & 38.40 & 239.10 & -9.72 & 1.92 \\
\hline C11 & 5 & 479.40 & 429.10 & 50.30 & 93.12 & -9.34 & 2.30 \\
\hline $\mathrm{C} 12$ & 20 & 482.45 & 444.40 & 38.05 & 125.45 & -9.02 & 2.62 \\
\hline
\end{tabular}

${ }^{a} N$ is the number of results in the clusters. ${ }^{b}$ Solvent-accessible surface area $\left(\AA^{2}\right)$ buried upon binding. ${ }^{c}$ In $\AA^{3}$. ${ }^{d}$ Binding free energy (kcal/ mol) calculated with the AutoDock software. ${ }^{e}$ Relative binding free energy (kcal/mol).

where $\Delta E_{\mathrm{MM}}$ represents the change in molecular mechanics potential energy upon formation of the complex, calculated using all bonded and nonbonded interactions. Solvation free energy penalty, $\Delta G_{\text {solv }}$, is composed of the electrostatic component $\left(G_{\mathrm{PB}}\right)$ and a nonpolar component $\left(G_{\mathrm{np}}\right)$ :

$$
\Delta G_{\mathrm{solv}}=\Delta G_{\mathrm{PB}}+\Delta G_{\mathrm{np}}
$$

$\Delta G_{\mathrm{PB}}$ was calculated solving the linear Poisson-Boltzmann (PB) equation by using the pbsa program. ${ }^{58}$ Dielectric constants of 1 and 80 were used for the interior and exterior, respectively.

The hydrophobic contribution to the solvation free energy, $\Delta G_{\mathrm{np}}$, is estimated using the equation

$$
\Delta G_{\mathrm{np}}=\alpha \mathrm{SASA}+\beta
$$

where SASA is the solvent-accessible surface area computed by means of the linear combination of pairwise overlap (LCPO) $\operatorname{method}^{62}$ with a solvent probe radius of $1.4 \AA$. The surface tension proportionality constant $\alpha$ and the free energy of nonpolar solvation for a point solute $\beta$ were set to its standard values, $0.00542 \mathrm{kcal} /\left(\mathrm{mol} \cdot \AA^{2}\right)$ and $0.92 \mathrm{kcal} / \mathrm{mol}$, respectively. ${ }^{68}$

The entropic contribution to the free energy (T $\Delta S$ ) was estimated by

$$
T \Delta S_{\text {solute }}=T\left(\Delta S_{\text {trans }}+\Delta S_{\text {rot }}+\Delta S_{\text {vib }}\right)_{\text {solute }}
$$

where $\Delta S_{\text {trans }}$ and $\Delta S_{\text {rot }}$ are the entropy contributions from translational and rotational motion calculated using classic statistics mechanics. ${ }^{67}$ The entropy contribution from vibrational motion $\left(\Delta S_{\text {vib }}\right)$ was obtained using normal mode calculations. Prior to the normal mode calculations, each snapshot was subjected to energy minimization using a distance dependent dielectric function $4 r_{i j}$ until a convergence lower than $10^{-4} \mathrm{kcal} /$ mol A. ${ }^{69}$

Since entropy calculations for large systems are extremely time-consuming, we applied this analysis to five snapshots taken at intervals of $200 \mathrm{ps}$ from the final $1.0 \mathrm{~ns}$ of the MD simulation. It should be emphasized that the $T \Delta S$ term is expected to be a crude approximation of only the solute entropy.

The per-residue binding energy decomposition was performed as explained elsewhere. ${ }^{70}$

The trajectories were analyzed using the ptraj module of the Amber package. ${ }^{58}$ The buried surface areas reported in Table 1 were calculated from the solvent-accessible surface area (SASA) using a probe radius of $1.4 \AA$ with the NACCESS program. ${ }^{71}$ The buried areas upon binding were calculated as the difference in the total SASA $\mathrm{ES}_{\mathrm{INH}}$ ternary complex and its components divided by 2 . The volumes reported in Table 1 were obtained with the ARVO program, ${ }^{72}$ with a $3 \AA$ protein film depth in the binding sites. The depth of the binding sites was considered as the distance between all ES atoms within $3 \AA$ from the INH. Ligand-protein contacts were analyzed with the ligand-protein contact (LPC) software. ${ }^{73}$

Experimental Section. The binding stoichiometry for the ES-INH ternary complexes, the dissociation constant $\left(K_{\mathrm{d}}\right)$, measured by direct titration of BACE1 and carried out at $\mathrm{pH}$ 4.5 and $25{ }^{\circ} \mathrm{C}$, the enthalpy $(\Delta H)$, the entropy $(\Delta S)$, and the Gibbs free energy $(\Delta G)$ of the reaction between the ES and several 5-mer to 12-mer exosite binding peptides were obtained by isothermal titration calorimetry experiments and published elsewhere. ${ }^{37}$

The structural coordinates defining a three-dimensional structure of a BACE1 exosite binding pocket are claimed in ref 38. Kornacker et al. ${ }^{38}$ showed that the ES-INH ternary complex crystallizes in the $P 2_{1} 2_{1} 2_{1}$ space group with one BACE1 dimer per asymmetric unit. The final model includes a BACE1 dimer, one Glu-Val-Asn-Phe- $\left(\mathrm{CH}(\mathrm{OH})-\mathrm{CH}_{2}\right)$-Ala-GluPhe peptide per molecule, 161 water molecules, and the exosite peptide Ac-TTYPYFIP-NH $\mathrm{N}_{2}$ in monomer $\mathrm{A}$ and the exosite peptide Ac-YPYFIPL-NH $\mathrm{NH}_{2}$ (i.e., INH) in monomer B. Unfortunately, to our knowledge, these coordinates are not in the public domain.

\section{Results and Discussion}

Blind Docking. In the first stage, we carried out a preliminary blind docking analysis using the Lamarckian genetic algorithm on BACE1, a globular protein with more than 380 residues, with the grid encompassing the whole BACE1 structure. Due to the large protein accessible surface area, numerous putative binding sites were found by the docking procedure (18 different putative sites). The solutions were sorted in terms of $\Delta G_{\text {bind, }}$, and the lowest docking energy conformations alone or the lowest docking energy conformations included in the largest cluster were considered to be the most stable orientations. Figure 1 shows the location of the 12 most representative and best ranked INH binding sites found from the blind docking procedure.

Several parameters of these 12 putative binding sites have been calculated as $\Delta G_{\text {bind }}, \Delta \Delta G_{\text {bind }}$, total, apolar, and polar accessible surface area buried between the BACE1 and the INH 


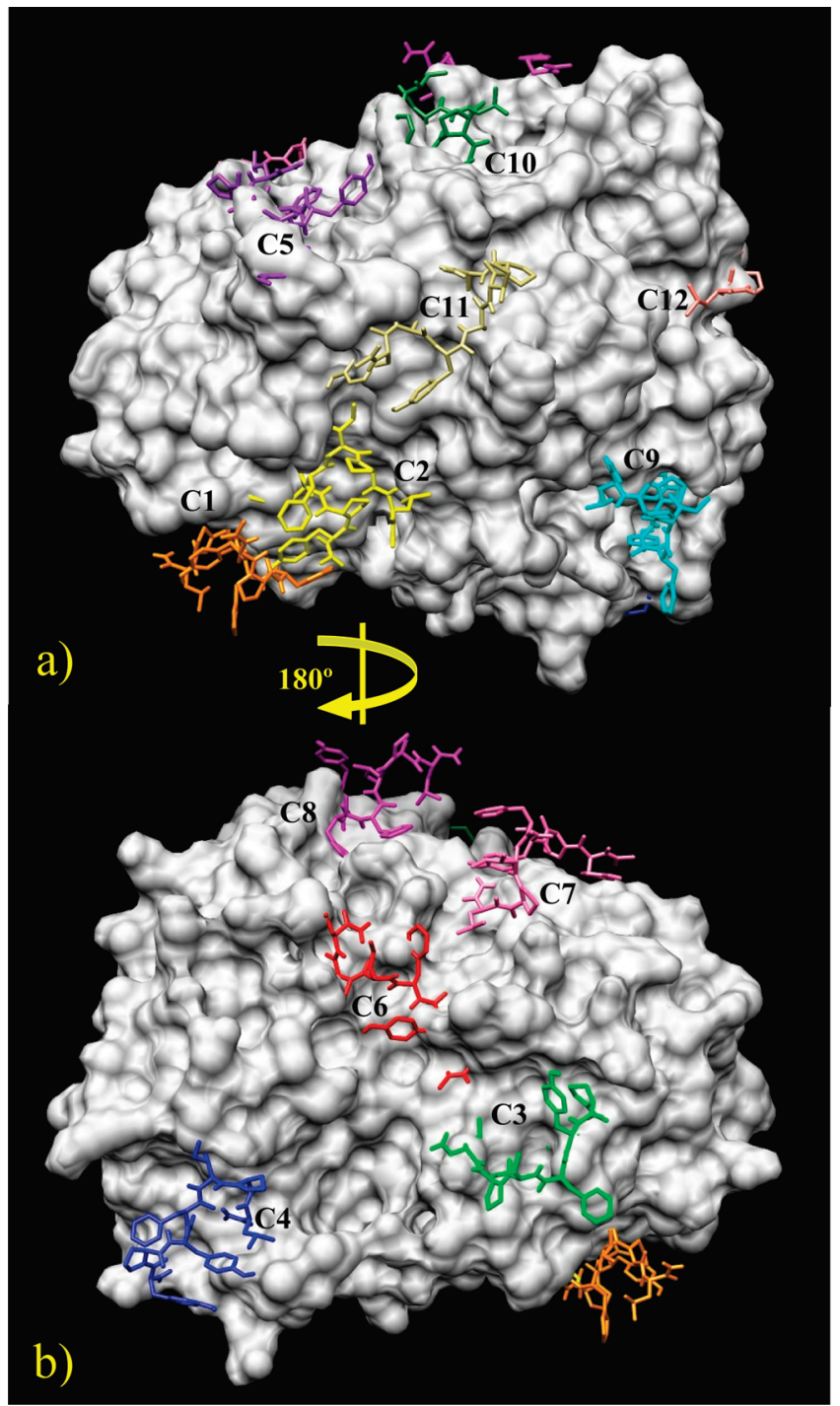

Figure 1. Blind docking results mapped onto the Connolly solventaccessible surface of the BACE1, viewed from two different angles. The 12 best ranked orientations are labeled from $\mathrm{C} 1$ to $\mathrm{C} 12$.

chain (Table 1). We can appreciate that the $\Delta G_{\text {bind }}$ obtained by the AutoDock software spans from -11.64 to $-9.02 \mathrm{kcal} / \mathrm{mol}$. Other docking solutions (six binding sites; results not shown) were also mapped on the BACE1 surface, but they all exhibited significantly less favorable energies of interactions (higher than $-9.02 \mathrm{kcal} / \mathrm{mol}$ ), suggesting that they were less likely to correspond to physiologically relevant ligand-binding sites, and therefore were disregarded. From Table 1, we may argue that the 12 sites are mostly hydrophobic, with some polar regions. Binding site 4 (i.e., C4) has the highest apolar buried area and volume, whereas binding site 10 (i.e., C10) has the lowest total and apolar buried areas.

As there is no experimental evidence of any significant conformational change upon binding, during the blind docking procedure, the ES complex was treated as a rigid body so the docking algorithms could be applied. Furthermore, such algorithms currently cannot treat a large number of torsional variables. However, the need to account for the dynamic behavior of the receptor has long been recognized as a critical factor in molecular recognition ${ }^{74,75}$ and in scoring binding affinities. ${ }^{76}$ Consequently, to refine the prediction of the blind docking for the BACE1-INH binding mode, a second stage by MD simulations was carried out for each of the complexes identified above.
TABLE 2: Mean Values for the Root-Mean-Square Displacement (rmsd) $(\AA)$ for the Listed Ternary Complexes $\mathrm{C} 1-\mathrm{C12}^{a}$

\begin{tabular}{cccc}
\hline & \multicolumn{3}{c}{ rmsd } \\
\cline { 2 - 4 } complex & protein & substrate & inhibitor \\
\hline C1 & $2.23(0.14)$ & $1.88(0.17)$ & $2.51(0.47)$ \\
C2 & $1.89(0.16)$ & $0.82(0.17)$ & $1.65(0.28)$ \\
C3 & $1.90(0.09)$ & $0.66(0.12)$ & $2.77(0.22)$ \\
C4 & $1.40(0.10)$ & $0.52(0.11)$ & $2.34(0.16)$ \\
C5 & $2.65(0.16)$ & $1.30(0.27)$ & $1.63(0.37)$ \\
C6 & $3.00(0.10)$ & $0.82(0.14)$ & $1.44(0.19)$ \\
C7 & $1.79(0.11)$ & $0.69(0.16)$ & $1.72(0.25)$ \\
C8 & $2.14(0.16)$ & $0.64(0.09)$ & $2.13(0.35)$ \\
C9 & $1.93(0.15)$ & $0.61(0.09)$ & $3.63(0.32)$ \\
C10 & $1.95(0.13)$ & $0.72(0.09)$ & $3.38(0.10)$ \\
C11 & $2.11(0.13)$ & $0.69(0.11)$ & $1.57(0.18)$ \\
C12 & $2.12(0.15)$ & $0.76(0.15)$ & $2.07(0.24)$ \\
& & &
\end{tabular}

${ }^{a}$ Values were obtained from the last $1.0 \mathrm{~ns}$ of MD. Standard deviations are indicated in parentheses.

Binding Mode. In a second stage, 12 MD simulations were performed, starting from the coordinates of each representative of the best ranked INH complexes, which were obtained from the above docking experiment. The complexes were subjected to $2.0 \mathrm{~ns} \mathrm{MD}$ simulation with the solvent effect taken into account through the generalized Born (GB) model. The aim of this stage was to generate more reasonable binding modes where the energy optimization and the dynamic flexibility of the BACE1, the substrate, and the inhibitor were explicitly considered.

To gauge whether the MD simulation was stable and converged, energetic and structural properties were monitored during the course of the trajectory. Because the energy conservation of a system is essential to its stability, and only the simulation of an energetically stable system can make sense, the evolutions of the temperature and selected energy terms were analyzed (see Figure 1-4 in the Supporting Information). These figures indicate that these energies reach equilibrium in a short time and oscillate around an average value after about $150 \mathrm{ps}$. This rapid convergence is correlated with the overall increase in mobility of GB simulations relative to explicit solvent simulations, and this is most probably due to the lack of frictional forces and the reorganization of water molecules to balance changes in solute structure. This observation implies that shorter GB trajectories may be sufficient to cover the sampling achieved in a longer explicit solvent simulation of the corresponding molecule. ${ }^{77}$ Table 1 in the Supporting Information lists the mean and standard deviation (SD) of these energies obtained from the last nanosecond of simulation. From Table 1 in the Supporting Information, we can appreciate that the unsigned SD is lower than the $\sim 1.4 \%$ from its mean value, supporting the idea that all systems become energetically well converged. To explore the dynamic flexibility of these ternary complexes and to ensure the rationality of the sampling strategy, the backbone $\mathrm{C} \alpha$ root-mean-square deviations (rmsd's) between snapshots obtained during the course of the trajectory and the original starting coordinates were calculated and plotted for each ternary complex component (i.e., BACE1, substrate and inhibitor, Figures 5-7 in the Supporting Information). As shown in Figures 5-7 in the Supporting Information, all complexes reach a plateau before the last nanosecond of simulation. These figures as well as Table 2 show that while the substrate displays no significant structural deviation from its starting coordinates (rmsd $\leq 1.88 \AA$ ), both the protein and the INH backbone deviate somewhat, rmsd $\leq 3.00 \AA$ and rmsd $\leq 3.63 \AA$, respectively. However, this is not a major issue that may impact the system 
TABLE 3: Binding Free Energy Components $(\mathrm{kcal} / \mathrm{mol})^{a}$

\begin{tabular}{|c|c|c|c|c|c|c|c|c|c|c|}
\hline \multirow[b]{2}{*}{ complex } & \multicolumn{10}{|c|}{ energy components } \\
\hline & $\Delta E_{\text {ele }}$ & $\Delta E_{\mathrm{vdw}}$ & $\Delta G_{\mathrm{pb}}$ & $\Delta G_{\mathrm{np}}$ & $\Delta G_{\text {ele,tot }}$ & $\Delta G_{\mathrm{np}, \mathrm{tot}}$ & $\Delta G_{\mathrm{tot}}$ & $-T \Delta S$ & $\Delta G_{\text {Bind }}$ & $\overline{\Delta \Delta G_{\text {Bind }}}$ \\
\hline $\mathrm{C} 1$ & -16.62 & -36.48 & 43.28 & -5.80 & 26.66 & -42.28 & -15.61 & 23.39 & 7.78 & 9.65 \\
\hline $\mathrm{C} 2$ & -39.12 & -56.47 & 81.50 & -8.50 & 42.38 & -64.97 & -22.57 & 26.01 & 3.44 & 5.31 \\
\hline $\mathrm{C} 3$ & -36.65 & -69.21 & 89.78 & -9.20 & 53.13 & -78.41 & -25.27 & 25.96 & 0.69 & 2.56 \\
\hline $\mathrm{C} 4$ & -38.42 & -45.68 & 60.79 & -6.61 & 22.37 & -52.29 & -29.51 & 27.64 & -1.87 & 0.00 \\
\hline C5 & -29.83 & -49.33 & 67.50 & -6.76 & 37.67 & -56.09 & -17.95 & 32.05 & 14.10 & 15.97 \\
\hline C6 & -38.68 & -64.69 & 82.90 & -9.27 & 44.22 & -73.96 & -29.73 & 31.93 & 2.20 & 4.07 \\
\hline $\mathrm{C} 7$ & -28.88 & -36.20 & 54.37 & -5.93 & 25.49 & -42.13 & -16.62 & 23.90 & 7.28 & 9.15 \\
\hline $\mathrm{C} 8$ & -28.04 & -37.31 & 58.04 & -5.88 & 30.00 & -43.19 & -13.16 & 20.96 & 7.80 & 9.67 \\
\hline C9 & -18.02 & -38.34 & 48.53 & -6.51 & 30.51 & -44.85 & -14.34 & 22.77 & 8.43 & 10.30 \\
\hline $\mathrm{C} 10$ & -18.08 & -47.45 & 53.53 & -6.28 & 35.45 & -53.73 & -18.27 & 19.83 & 1.56 & 3.43 \\
\hline $\mathrm{C} 11$ & -28.16 & -40.34 & 53.78 & -6.37 & 25.62 & -46.71 & -21.07 & 20.99 & -0.08 & 1.79 \\
\hline $\mathrm{C} 12$ & -44.03 & -39.42 & 62.61 & -6.24 & 18.58 & -45.66 & -27.06 & 27.83 & 0.77 & 2.64 \\
\hline
\end{tabular}

${ }^{a}$ Values are averaged over 100 snapshots extracted at regular time intervals during the last $1.0 \mathrm{~ns}$ of MD. The energy components were calculated according to the Methods section. $1 \mathrm{kcal}=4.18 \mathrm{~kJ}$.

stability. Moreover, these results indicate that the systems are stable as a whole and their flexibility changes to some extent.

A more detailed analysis calculating the root-mean-square fluctuations (rmsf's) versus residue number for the 12 BACE1 complexes is illustrated in Figure 8 in the Supporting Information. As a general characteristic, the BACE1 structures showed similar rmsf distribution and similar trends of dynamic features in all complexes. Except for some obviously high fluctuations, regions around the catalytic dyad (Asp32 and Asp228) showed somewhat rigid behavior.

From the above results, we assume well-behaved and converged simulations that achieve a reasonable amount of sampling for each component of the ternary complexes (i.e., BACE1, substrate, and inhibitor), suggesting that no significant structural deviations from its starting structures occurred. Moreover, the calculated rmsd and rmsf at this stage are similar to previous related systems, ${ }^{78,79}$ although such reports were focused on the conformational flexibility of bound and unbound BACE1-substrate analogues in explicit solvent instead of the ternary complexes analyzed herein.

Energetic Analysis of the Binding. By the MM-PBSA analysis, ${ }^{67}$ the total free energy of binding into electrostatic, van der Waals, and solute-solvent interactions could be separated, gaining, thus, additional insights into the physics of the BACE1-INH association process. For this energetic analysis, a single trajectory method was performed in order to score the mode of binding by calculating the binding free energies. For this analysis, 100 equally spaced snapshots were taken at intervals of $10 \mathrm{ps}$ from the last $1.0 \mathrm{~ns}$ of each MD trajectory. The binding free energy and the energy components of the complexes are summarized in Table 3.

According to Table 3, electrostatic ( $\left.\Delta E_{\text {ele }}\right)$ and van der Waals $\left(\Delta E_{\mathrm{vdw}}\right)$ terms in the gas phase provide the major favorable contributions to the INH binding, whereas polar solvation energies $\left(\Delta G_{\mathrm{pb}}\right)$ impair the binding. The nonpolar solvation energies $\left(\Delta G_{\mathrm{np}}\right)$, which correspond to the burial of SASA upon binding, barely contribute to the INH binding.

Further insight into the forces involved in BACE1-INH ternary complex formation can be obtained by analyzing the electrostatic $\left(\Delta G_{\text {ele,tot }}\right)$ and nonelectrostatic $\left(\Delta G_{\text {np,tot }}\right)$ contributions in Table 3. As demonstrated by numerous studies, the electrostatic contribution generally disfavors the docking of ligand and receptor molecules because the unfavorable change in the electrostatics of solvation is mostly, but not fully, compensated by the favorable electrostatics within the resulting ligand-receptor complex..$^{70,80,81}$ Indeed, from Table 3, we can appreciate that, despite the favorable electrostatic energies in the gas phase $\left(\Delta E_{\text {ele }}\right)$, the contributions of polar solvation energies to binding $\left(\Delta G_{\mathrm{pb}}\right)$ are unfavorable for the 12 complexes, and the $\Delta G_{\text {ele,tot }}$, the sum of $\Delta E_{\text {ele }}$ and $\Delta G_{\mathrm{pb}}$, does not favor the binding. Table 3 also suggests that the net result of nonelectrostatic interaction $\left(\Delta G_{\mathrm{np}, \mathrm{tot}}\right)$, the sum of $\Delta E_{\mathrm{vdw}}$ and $\Delta G_{\mathrm{np}}$, is favorable for the formation of the 12 complexes, and it should be noted that this behavior has been proposed previously as a general trend for noncovalent ligand-receptor associations. ${ }^{82}$ From the above results, we can conclude that the binding free energies obtained for these complexes are driven by more favorable nonpolar interactions rather than by electrostatic interactions. These results are in agreement with Table 1, which shows that the located binding sites in the surface of the BACE1 target are mostly hydrophobic.

Although the net $\Delta G_{\text {tot }}$, the sum of enthalpic and desolvation terms, remained favorable across all of the complexes, covering a range from -29.73 to $-13.16 \mathrm{kcal} / \mathrm{mol}$, the solute entropic contributions $\left(T \Delta S_{\text {tot }}\right)$ are of the same magnitude but unfavorable. This opposing interplay between enthalpy and entropy is known as enthalpy/entropy compensation and is a fundamental property of noncovalent interactions. ${ }^{83,84}$ This enthalpy/entropy compensation results in small changes in $\Delta G$ values. ${ }^{85}$ More importantly, it is not confined to binding in aqueous solution, ${ }^{86}$ nor should it be ascribed to errors of measurement. ${ }^{87,88}$ It arises because bonding opposes motion and, also reciprocally, motion opposes bonding. The two effects can be traded off against each other because the strength of noncovalent bonds is, at room temperature, comparable to the thermal energies that oppose them. ${ }^{84}$

The inclusion of the solute entropic contributions appears to be important, as evidenced by a substantial reordering of the binding free energies ( $\left.\Delta G_{\text {bind }}\right)$ after taking the entropic term into consideration.

As was recently reviewed, ${ }^{89,90}$ allostery is a purely thermodynamic phenomenon in which a binding event leads to loss of freedom of motion of the binding partners, including their internal motions; thus, it is entropy-unfavorable. Besides, a disorder-to-order transition generally involves formation of a more cooperative set of interactions within the protein that replaces a less cooperative set of interactions between the protein and the solvent. Then, the added ligand-receptor interactions are enthalpy-favorable because, during binding, the interactions get increasingly tighter. Concordantly, the above-mentioned trend is followed by the complexes analyzed herein, as shown by the results listed in Table 3 . 
TABLE 4: Residues in the Binding Site 4 (i.e., C4) at Less than $6 \AA$ from the Best Docked Conformation, as Found by Refined MD (the Matching Positions Are Shown in Bold Font)

\begin{tabular}{|c|c|c|c|}
\hline \multicolumn{2}{|c|}{ residue } & \multicolumn{2}{|c|}{ binding site } \\
\hline name & number ${ }^{a, b}$ & ref 38 & $\overline{\mathrm{MD}^{c}}$ \\
\hline Gln & $163(224)$ & - & + \\
\hline Glu & 255 (316) & + & + \\
\hline Lys & $256(317)$ & + & + \\
\hline Phe & 257 (318) & + & + \\
\hline Pro & 258 (319) & + & + \\
\hline Asp & $259(320)$ & - & + \\
\hline Phe & $261(322)$ & + & + \\
\hline Gly & $264(325)$ & + & + \\
\hline Glu & $265(326)$ & + & + \\
\hline Gln & $266(327)$ & + & + \\
\hline Leu & $267(328)$ & + & + \\
\hline Val & 268 (329) & + & + \\
\hline Cys & $269(330)$ & + & + \\
\hline Trp & $270(331)$ & + & + \\
\hline Gln & $271(332)$ & + & + \\
\hline Ala & $272(333)$ & + & + \\
\hline Gly & $273(334)$ & - & + \\
\hline Thr & $274(335)$ & + & - \\
\hline Asp & 311 (372) & + & + \\
\hline Val & $312(373)$ & + & + \\
\hline Ala & $313(374)$ & + & + \\
\hline Ser & 315 (376) & + & + \\
\hline Asp & 317 (378) & + & + \\
\hline Asp & 318 (379) & + & + \\
\hline Cys & 319 (380) & + & + \\
\hline Tyr & $320(381)$ & + & + \\
\hline Phe & $322(383)$ & - & + \\
\hline
\end{tabular}

${ }^{a}$ Amino acid numbering based on PDB entry $1 \mathrm{M} 4 \mathrm{H} .{ }^{b}$ Amino acid numbering based on GenBank accession number NP_036236. ${ }^{c}$ This work.

In this work, the objective was to find the location as well as the structural and thermodynamic characteristics of the exosite on the human BACE1, starting from "ad hoc" models. It should be noted that the inadequacies of the models, the implicit limitations of the method, and the simplifications in its applications should be canceled when the relative free energies ( $\left.\Delta \Delta G_{\text {bind }}\right)$ rather than absolute $\left(\Delta G_{\text {bind }}\right)$ energies are calculated. ${ }^{91}$

Considering the relative binding free energies listed in Table 3 , complex 4 (i.e., C4) emerges as the best ranked from the 12 analyzed complexes. This result is highly encouraging because the identified binding site, where the INH fits the BACE1 target in complex 4 , is in complete agreement with the experimental observations, suggesting that the docked structure obtained for complex 4 is an adequate representation of the functional complex. ${ }^{38}$ Thus, it is more prudent and certainly not inconsistent with the above results to analyze deeply the structural characteristics and thermodynamic properties of the binding site in complex 4 rather than those in all the docked complexes. However, a second ranked binding site labeled as $\mathrm{C} 11$, with $\Delta \Delta G_{\text {bind }} \sim 1.79 \mathrm{kcal} / \mathrm{mol}$, located $\sim 48.67 \pm 7.51 \AA$ away from binding site 4 should not be disregarded as another putative allosteric site. The most important residual contacts of the INH located at this second ranked binding site $\mathrm{C} 11$ are shown in Table 2 in the Supporting Information.

Mapping the Binding Site in Complex 4. Focusing on the high affinity binding site identified by the energetic analysis of binding calculations, we define the binding site in complex 4 as those residues being within approximately $6 \AA$ from any INH atom. These residues are listed in Table 4. Interestingly, the great majority of the residues listed in Table 4 are supported

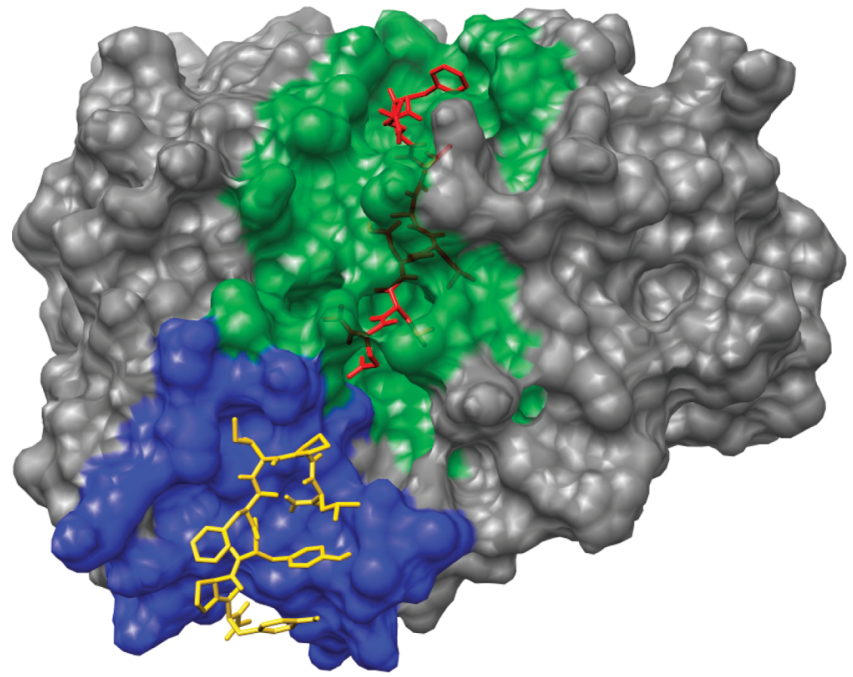

Figure 2. Refined MD result for complex 4, taken at $2.0 \mathrm{~ns}$ of the MD simulation, mapped onto the Connolly solvent-accessible surface of the BACE1. The active cleft is shown as the green region, whereas the residues forming the inhibitor binding site are shown in blue. The substrate and the inhibitor are shown as red and yellow sticks, respectively.

by experimental data. ${ }^{38}$ However, with the exception of Thr274 that was not found in our calculations, in our dynamic model, we also identified Gln163, Asp259, Gly273, and Phe322 to be within the proposed cutoff of $6 \AA$ from the INH.

Figure 2 shows the location of the INH at binding site 4 refined by $\mathrm{MD}$ results. We can appreciate that, whereas the substrate (in red) is located in the binding cleft between the $\mathrm{NH}_{2}$ lobe (residues 1-180) and $\mathrm{COOH}$ lobe (residues 181-385) and partially covered by the hairpin loop, known as the "flap" (residues 69-75), ${ }^{28}$ the INH (in yellow) is located in the $\mathrm{COOH}$ lobe laying over the $\beta$-sheet that spans from residue 266 to residue 273 and protrudes to the catalytic cleft. This structural feature would support the experimental results in which the INH (and related) peptides inhibited the BACE1-mediated cleavage of the MBP-APP(547-695) fusion protein in a concentrationdependent fashion. ${ }^{37}$ In other words, we argue that the peptide occupancy at the exosite (i.e., binding site 4) would affect the binding and cleavage of large substrates that encompass more residues of the APP protein sequence, probably by steric hindrances on the catalytic cleft. This is not inconsistent with an allosteric control of BACE1 because solid evidence that has been accumulated clearly indicates that allostery can be at play even in the absence of changes in the shape of a receptor. ${ }^{89,92}$

To better understand the intermolecular interactions between each residue of the INH and the residues forming the binding site in complex 4, Table 5 lists the residue name and number, distances and contact surfaces of aromatic, stabilizing hydrophobic, destabilizing hydrophobic-hydrophilic, and hydrogen bonding interactions. We can appreciate that the INH residues Tyr1, Tyr3, and Leu7 may strengthen the binding to the BACE1 at their binding site mainly by hydrogen bonds, whereas Pro2, Phe4, and Ile5 are involved in aromatic and/or hydrophobic contacts. However, no interaction takes place between the Pro6 residue on the INH and any BACE1 residue forming the binding site in complex 4.

To investigate which residues of the binding site identified in complex 4 determine the binding affinities for the INH, an inhibitor-residue free energy decomposition analysis ${ }^{70}$ was performed. Thus, the most important residues located in the BACE1 binding site should show the strongest interactions. 
TABLE 5: Identified Residual Contacts between BACE1 and the INH in the Average Structure from the Last $1.0 \mathrm{~ns}$ of $\mathrm{MD}^{a}$

\begin{tabular}{|c|c|c|c|c|c|c|c|c|c|c|c|c|c|c|c|c|c|c|c|}
\hline \multirow[b]{3}{*}{ interactions } & \multicolumn{19}{|c|}{ inhibitor residue } \\
\hline & \multicolumn{3}{|c|}{ Tyr1 } & \multicolumn{3}{|c|}{ Pro2 } & \multicolumn{3}{|c|}{ Tyr3 } & \multicolumn{3}{|c|}{ Phe4 } & \multicolumn{3}{|c|}{ Ile 5} & Pro6 & \multicolumn{3}{|c|}{ Leu7 } \\
\hline & $\begin{array}{l}\mathrm{BACE} 1 \\
\text { residue }\end{array}$ & dist. & surf. & $\begin{array}{l}\mathrm{BACE} 1 \\
\text { residue }\end{array}$ & dist. & surf. & $\begin{array}{l}\mathrm{BACE} 1 \\
\text { residue }\end{array}$ & dist. & surf. & $\begin{array}{l}\text { BACE1 } \\
\text { residue }\end{array}$ & dist. & surf. & $\begin{array}{l}\mathrm{BACE} 1 \\
\text { residue }\end{array}$ & dist. & surf. & $\begin{array}{l}\text { BACE1 } \\
\text { residue dist. surf. }\end{array}$ & $\begin{array}{l}\mathrm{BACE} 1 \\
\text { residue }\end{array}$ & dist. & surf. \\
\hline $\begin{array}{r}\text { aromatic- } \\
\text { aromatic }\end{array}$ & & & & Trp270 & 3.7 & 32.3 & & & & Phe257 & 5.4 & 5.4 & & & & & & & \\
\hline hydrophobic- & Asp317 & 2.7 & 36.3 & & & & Leu267 & 4.4 & 4.9 & Pro258 & 4.2 & 26.9 & $\mathrm{G} \ln 266$ & 5.0 & 8.3 & & Gln163 & 4.9 & 13.5 \\
\hline & & & & & & & Asp311 & 4.4 & 25.3 & & & & & & & & $\begin{array}{r}\text { Leu267 } \\
\text { Val312 }\end{array}$ & $\begin{array}{l}3.0 \\
5.8\end{array}$ & $\begin{array}{r}40.1 \\
5.6\end{array}$ \\
\hline $\begin{array}{l}\text { hydrophobic- } \\
\text { hydrophilic }\end{array}$ & Thr314 & 5.6 & 8.5 & & & & Cys269 & 2.9 & 59.5 & Gln266 & 5.4 & 1.7 & Pro258 & 5.1 & 11.0 & & $\mathrm{G} \ln 266$ & 3.7 & 8.1 \\
\hline & Asp317 & 2.7 & 36.3 & & & & & & & $\begin{array}{r}\text { Leu267 } \\
\text { Val268 }\end{array}$ & $\begin{array}{l}3.9 \\
4.5\end{array}$ & $\begin{array}{l}3.9 \\
8.7\end{array}$ & $\mathrm{G} \ln 266$ & 5.0 & 8.3 & & $\begin{array}{l}\text { Leu267 } \\
\text { Lys321 }\end{array}$ & $\begin{array}{l}3.0 \\
5.2\end{array}$ & $\begin{array}{r}40.1 \\
1.0\end{array}$ \\
\hline hydrogen bond & $\begin{array}{l}\text { Trp270 } \\
\text { Asp317 }\end{array}$ & $\begin{array}{l}3.9 \\
2.7\end{array}$ & $\begin{array}{r}4.5 \\
36.3\end{array}$ & & & & $\begin{array}{l}\text { Cys269 } \\
\text { Asp311 }\end{array}$ & $\begin{array}{l}2.9 \\
4.4\end{array}$ & $\begin{array}{l}59.5 \\
25.3\end{array}$ & & & & & & & & Leu267 & 3.0 & 40.1 \\
\hline
\end{tabular}

a Abbreviations: dist., atomic distance $(\AA)$; surf., surface contact area $\left(\AA^{2}\right)$.

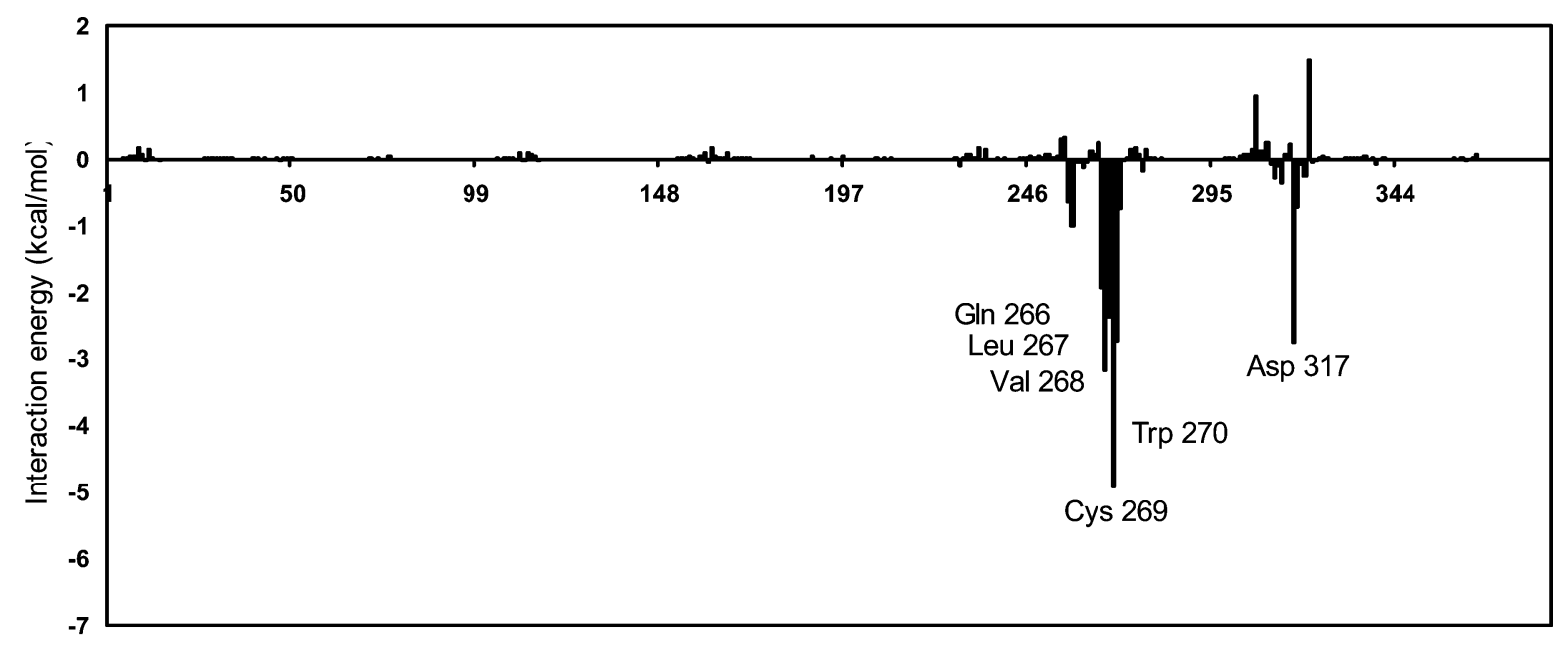

\section{BACE1 secuence}

Figure 3. Histogram of interaction energies partitioned with respect to the BACE1 amino acids in complex 4 (i.e., C4). The $x$-axis denotes the residue number of BACE1, and the $y$-axis denotes the energy between the inhibitor and specific residues. The reference state is separate BACE1 and $\mathrm{INH}$, with negative values favorable and positive values unfavorable to binding.

Figure 3 shows the results of this analysis plotting the $\Delta G_{\text {tot }}$ contribution (which includes van der Waals and electrostatic interactions, polar solvation contribution, and nonpolar solvation contribution) versus each BACE1 residue. It should be noted that these energy values are focused on individual contributions and are distinct from the calculations of total free energy values listed in Table 3. According to the free energy decomposition analysis (Figure 3), the binding between the BACE1 and the INH located at binding site 4 is driven by selected "hot spots" that play a major role in BACE1-INH recognition. Interestingly, the most important residues are, once again, Gln266, Leu267, Val268, Cys269, Trp270, and Asp317, which were found to be involved in several interactions of different types with the INH (see Table 5). In addition, these residues are found in Table 4, forming the core region of the allosteric binding site, and all of them are fully supported by experimental results. ${ }^{38}$

A corresponding analysis referenced to the INH is shown in Figure 4. Here, as expected, strongly favorable contributions to the binding are associated with some INH residues at allosteric binding site 4. However, while Pro2, Ile5, and Pro6 contribute weakly to the binding, Tyr1, Tyr3, Phe4, and Leu7 make strong contributions corroborating the intermolecular interaction results shown in Table 5 .

In summary, from the results shown in Table 5, we can argue that the higher number of hydrogen bonds, aromatic, and/or hydrophobic interactions and less hydrophobic-hydrophilic

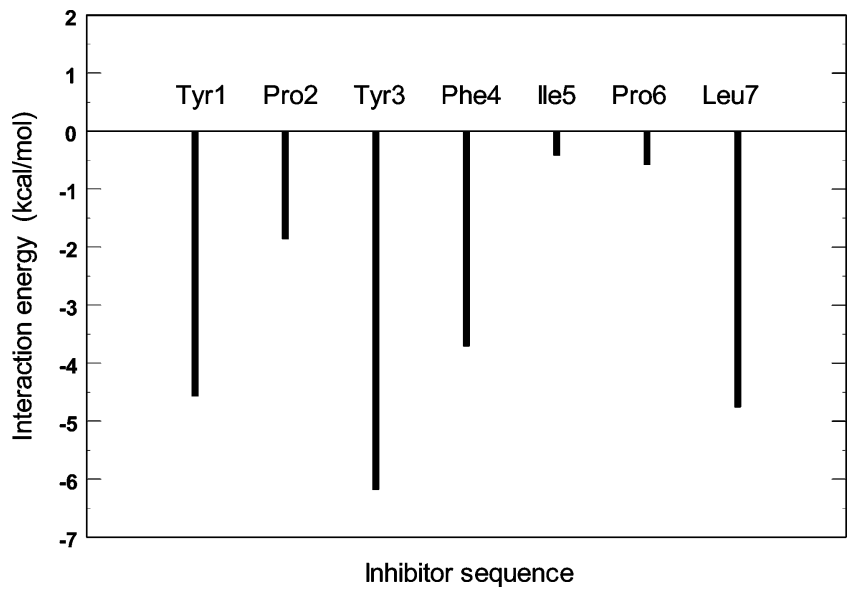

Figure 4. Histogram of interaction energies partitioned with respect to the inhibitor (i.e., INH) amino acids. The $x$-axis denotes the residue number of INH, and the $y$-axis denotes the energy between the inhibitor and the BACE upon binding. The reference state is the unbound INH, with negative values favorable and positive values unfavorable to binding.

(destabilizing) interactions between the BACE1 and the INH residues in complex 4 (i.e., C4) might explain the interaction energy trend by the INH residues shown in Figure 4. 
To our knowledge, a complete structural description for the exosite associated with BACE1 has not been reported yet. Only partial information about the location and a list of the amino acids located at $6 \AA$ from the inhibitor might be obtained from ref 38 sections 0058 . From our results, a complete structural description for this exosite, including the different interaction stabilizing the BACE1-INH complex, was obtained. The full coordinates of this complex are available from the authors upon request.

\section{Conclusions}

Twelve binding pockets were identified on the surface of BACE1 by blind docking studies. MD were performed to refine the docked structures and to investigate the binding mode on each ternary complex. The results indicate that the systems are stable as a whole and their flexibility changes to some extent. The calculations of binding free energies for the 12 complexes using MM-PBSA methods showed that van der Waals interactions dominated the binding of these complexes. On the other hand, the best ranked ternary complex showed convincing consistency with experimentally determined data described in the literature. ${ }^{38}$

In agreement with the structure of the INH peptide obtained from an X-ray study, ${ }^{38}$ residues Glu255-Pro258, Phe261, Gly264-Ala272, Asp311-Ala313, Ser315, and Asp317-Tyr320 are located within $\sim 6 \AA$ from the INH at the exosite binding site. ${ }^{38}$ The simulations revealed that the topological occupancy of the INH at the BACE1 exosite would affect the binding and cleavage of large substrates that encompass more APP protein residues by steric hindrances on the catalytic cleft.

Energy decomposition on a per-residue basis for the best ranked complex (i.e., C4) showed that residues Gln266, Leu267, Val268, Cys269, Trp270. and Asp317 can be identified as hot spots to the BACE1-INH ternary complex formation. We found that favorable interactions are produced between the BACE1 and the INH residues Tyr1, Tyr3, Phe4, and Leu7. In addition, on the basis of the hydrogen bond analysis, the hydrogen bonds formed between the INH peptide, residues Tyr1, Tyr3, and Leu7, with the BACE1 residues Leu267, Cys269, Trp270, Asp311, and Asp 317 were shown to strengthen the binding of the BACE1-INH complex.

Our results suggest that the design of new and more potent allosteric inhibitors can be synthesized replacing INH positions Pro2, Ile5, and/or Pro6 in order to optimize the affinity for the exosite. Since the binding affinity is determined by the Gibbs energy $K a=\exp (-\Delta G / R T)$ and $\Delta G$ is given by $\Delta G=\Delta H-$ $T \Delta S,{ }^{93}$ it is apparent that binding optimization can be accomplished by making either $\Delta H$ more negative or $\Delta S$ more positive, or by an appropriate combination of both. The above could allow us to propose one of the following modifications on the INH: (i) to replace positions 2, 5, and/or 6 with low desolvation energy amino acids, like Ala, Ile, Leu, and Val; (ii) to replace these positions with high degree of freedom amino acids, like Ile, Leu, and Val; or (iii) to apply an appropriate combination of both.

This is the first report on a molecular modeling approach on an exosite associated with BACE1 carried out from the experimental data available in the literature. ${ }^{37,38}$ We believe that understanding the exosite interactions at the atomic level may help for the development of novel BACE1 inhibitors with better potency and efficacy, being useful as chemotherapeutic agents for the treatment of Alzheimer's disease. Moreover, the results of this study clearly indicate the significance of the applied computational methods to provide insight into protein complexes on an atomic level even when limited experimental information is available.

Acknowledgment. Grants from Universidad Nacional de San Luis (UNSL), FONCyT-ANPCyT (PAE 02-22642), and from UNSL P-328402 supported this work. R.D.E. and H.A.B. are staff members of the National Research Council of Argentina (CONICET-Argentina). L.J.G. gratefully acknowledges a CONICET fellowship.

Supporting Information Available: Time series of the temperature, total, potential, and kinetic energy, BACE1 backbone rmsd, substrate backbone rmsd, inhibitor backbone rmsd, as well as BACE1-INH complexes RMSF are shown in Figures $1-8$, respectively. Mean values and standard deviations of selected energy component are listed in Table 1. In addition, the identified residual contacts between BACE1 and the inhibitor located at the second ranked binding site are listed in Table 2. This material is available free of charge via the Internet at http:// pubs.acs.org.

\section{References and Notes}

(1) Melnikova, I. Nat. Rev. Drug Discovery. 2007, 6, 341-342.

(2) Van Marum, R. J. Fundam. Clin. Pharmacol. 2008, 22, 265-274.

(3) Nguyen, J. T.; Yamani, A.; Kiso, Y. Curr. Pharm. Des. 2006, 12, 4295-4312.

(4) Hardy, J.; Selkoe, D. J. Science 2002, 297, 353-356.

(5) Olson, R. E.; Copeland, R. A.; Seiffert, D. Curr. Opin. Drug Discovery Dev. 2001, 4, 390-401.

(6) Josepha, J.; Shukitt-Hale, B.; Denisova, N. A.; Martin, A.; Perry, G.; Smith, M. A. Neurobiol. Aging 2001, 22, 131-146.

(7) Stockley, J. H.; O'Neill, C. Cell. Mol. Life Sci. 2008, 65, 32653289.

(8) Ghosh, A. K.; Gemma, S.; Tang, J. Neurotherapeutics 2008, 5, 399-408.

(9) Crouch, P. J.; Harding, S. M. E.; White, A. R.; Camakaris, J.; Bush, A. I.; Masters, C. L. Int. J. Biochem. Cell Biol. 2008, 40, 181-198.

(10) Dillen, K.; Annaert, W. A. Int. Rev. Cytol. 2006, 254, 215-300.

(11) Vardy, E. R. L. C.; Catto, A. J.; Hooper, N. M. Trends Mol. Med.

2005, 11, 464-472.

(12) Vassar, R. J. Mol. Neurosci. 2004, 23, 105-113.

(13) Huse, J. T.; Doms, R. W. Mol. Neurobiol. 2001, 22, 81-98.

(14) Sabbagh, M. N.; Galasko, D.; Koo, E.; Thal, L. J. J. Alzheimer's Dis. 2000, 2, 231-259.

(15) Pavia, J.; De Ceballos, M.; Sanchez De la Cuesta, F. Fundam. Clin. Pharmacol. 1998, 12, 473-481.

(16) Suh, Y. H. J. Neurochem. 1997, 68, 1781-1791.

(17) Vassar, R.; Bennett, B. D.; Babu-Khan, S.; Kahn, S.; Mendiaz, E. A.; Denis, P.; Teplow, D. B.; Ross, S.; Amarante, P.; Loeloff, R.; Luo, Y.; Fisher, S.; Fuller, J.; Edenson, S.; Lile, J.; Jarosinski, M. A.; Biere, A. L.; Curran, E.; Burgess, T.; Louis, J. C.; Collins, F.; Treanor, J.; Rogers, G.; Citron, M. Science 1999, 286, 735-741.

(18) Lin, X.; Koelsch, G.; Wu, S.; Downs, D.; Dashti, A.; Tang, J. Proc. Natl. Acad. Sci. U.S.A. 2000, 97, 1456-1460.

(19) Yan, R.; Bienkowski, M. J.; Shuck, M. E.; Miao, H.; Tory, M. C.; Pauley, A. M.; Brashler, J. R.; Stratman, N. C.; Mathews, W. R.; Buhl, A. E.; Carter, D. B.; Tomasselll, A. G.; Parodl, L. A.; Helnrikson, R. L.; Gurney, M. E. Nature 1999, 402, 533-537.

(20) Sinha, S.; Anderson, J. P.; Barbour, R.; Basi, G. S.; Caccaveffo, R.; Davis, D.; Doan, M.; Dovey, H. F.; Frigon, N.; Hong, J.; JacobsonCroak, K.; Jewett, N.; Keim, P.; Knops, J.; Lieberburg, I.; Power, M.; Tan, H.; Tatsuno, G.; Tung, J.; Schenk, D.; Seubert, P.; Suomensaari, S. M.; Wang, S.; Walker, D.; Zhao, J.; McConlogue, L.; John, V. Nature 1999, 402, 537-540.

(21) Hussain, I.; Powell, D.; Howlett, D. R.; Tew, D. G.; Meek, T. D.; Chapman, C.; Gloger, I. S.; Murphy, K. E.; Southan, C. D.; Ryan, D. M.; Smith, T. S.; Simmons, D. L.; Walsh, F. S.; Dingwall, C.; Christie, G. Mol. Cell. Neurosci. 1999, 14, 419-427.

(22) Ghosh, A. K.; Hong, L.; Tang, J. Curr. Med. Chem. 2002, 9, 11351144.

(23) Ghosh, A. K.; Kumaragurubaran, N.; Tang, J. Curr. Top. Med. Chem. 2005, 5, 1609-1622.

(24) Thompson, L. A.; Bronson, J. J.; Zusi, F. C. Curr. Pharm. Des. 2005, 11, 3383-3404.

(25) John, V. Curr. Top. Med. Chem. 2006, 6, 569-578. 
(26) Durham, T. B.; Shepherd, T. A. Curr. Opin. Drug Discovery Dev. 2006, 9, 776-791.

(27) (a) Hills, I. D.; Vacca, J. P. Curr. Opin. Drug Discovery Dev. 2007, 10, 383-391. (b) Katharine Holloway, M.; Hunt, P.; McGaughey, G. B. Drug Dev. Res. 2009, 70, 70-93. (c) Yi Mok, N.; Chadwick, J.; Kellett, K. A. B.; Hooper, N. M.; Jonson, A. P.; Fishwick, C. W. G. Bioorg. Med. Chem. Lett. 2009, 19, 6770-6774.

(28) Hong, L.; Koelsch, G.; Lin, X.; Wu, S.; Terzyan, S.; Ghosh, A. K.; Zhang, X. C.; Tang, J. Science 2000, 290, 150-153.

(29) Hong, L.; Turner, R. T.; Koelsch, G.; Shin, D.; Ghosh, A. K.; Tang, J. Biochemistry 2002, 41, 10963-10967.

(30) Turner III, R. T.; Hong, L.; Koelsch, G.; Ghosh, A. K.; Tang, J. Biochemistry 2005, 44, 105-112.

(31) Turner III, R. T.; Koelsch, G.; Hong, L. Biochemistry 2001, 40, 10001-10006.

(32) Krishnaswamy, S.; Betz, A. Biochemistry 1997, 36, 12080-12086.

(33) Horiuchi, K. Y.; Scherle, P. A.; Trzaskos, J. M.; Copeland, R. A. Biochemistry 1998, 37, 8879-8885.

(34) Maun, H. R.; Eigenbrot, C.; Lazarus, R. A. J. Biol. Chem. 2003, $278,21823-21830$.

(35) Das, C.; Berezovska, O.; Diehl, T. S.; Genet, C.; Buldyrev, I.; Tsai, J. Y.; Hyman, B. T.; Wolfe, M. S. J. Am. Chem. Soc. 2003, 125, 1179411795 .

(36) Ng, K. K.; Petersen, J. F.; Cherney, M. M.; Garen, C.; Zalatoris, J. J.; Rao-Naik, C.; Dunn, B. M.; Martzen, M. R.; Peanasky, R. J.; James, M. N. Nat. Struct. Biol. 2000, 7, 653-657.

(37) Kornacker, M. G.; Lai, Z.; Witmer, M.; Ma, J.; Hendrick, J.; Lee, V. G.; Riexinger, D. J.; Mapelli, C.; Metzler, W.; Copeland, R. A. Biochemistry 2005, 44, 11567-11573.

(38) Kornacker, M. G.; Copeland, R. A.; Hendrick, J.; Lai, Z.; Mapelli, C.; Witmer, M. R.; Marcinkeviciene, J.; Metzler, W.; Lee, V.; Riexinger, D. J. US Patent 7314726, 2008 (http://www.freepatentsonline.com/ 7314726.html).

(39) Berman, H. M.; Westbrook, J.; Feng, Z.; Gilliland, G.; Bhat, T. N.; Weissig, H.; Shindyalov, I. N.; Bourne, P. E. Nucleic Acids Res. 2000, 28 , 235-242.

(40) Grüninger-Leitch, F. J. Biol. Chem. 2002, 277, 4687-4693.

(41) Gordon, J. C.; Myers, J. B.; Folta, T.; Shoja, V.; Heath, L. S.; Onufriev, A. Nucleic Acids Res. 2005, 33, 368-71.

(42) Anandakrishnan, R.; Onufriev, A. J. Comput. Biol. 2008, 15, 165184

(43) Bashford, D.; Karplus, M. Biochemistry 1990, 29, 10219-10225.

(44) Park, H.; Lee, S. J. Am. Chem. Soc. 2003, 125, 16416-16422.

(45) Rajamani, R.; Reynolds, C. H. J. Med. Chem. 2004, 47, 51595166.

(46) Suguna, K.; Padlan, E. A.; Smith, C. W.; Carlson, W. D.; Davies,

D. R. Proc. Natl. Acad. Sci. U.S.A. 1987, 84, 7009-7013.

(47) Davies, D. R. Biophys. Chem. 1990, 19, 189-215.

(48) Coupez, B.; Lewis, R. A. B. Curr. Med. Chem. 2006, 13, 29812993.

(49) Alonso, H. A.; Bliznyuk, A. A.; Gready, J. E. Med. Res. Rev. 1996, $26,531-568$

(50) (a) Goodsell, D. S.; Morris, G. M.; Olson, A. J. J. Mol. Recognit. 1996, 9, 1-5. (b) Morris, G. M.; Goodsell, D. S.; Halliday, R. S.; Huey, R.; Hart, W. E.; Belew, R. K.; Olson, A. J. J. Comput. Chem. 1998, 19, 16391662 .

(51) Hetényi, C.; Van Der Spoel, D. FEBS Lett. 2006, 580, 1447-1450. (52) Ghersi, D.; Sanchez, R. Proteins: Sruct., Funct., Bioinf. 2009, 74, $417-424$.

(53) Vaque, M.; Ardévol, A.; Bladé, C.; Salvadó, M. J.; Blay, M.; Fernández-Larrea, J.; Arola, L.; Pujadas, G. Curr. Pharm. Anal. 2008, 4, $43-466$.

(54) Iorga, B.; Herlem, D.; Barré, E.; Guillou, C. J. Mol. Model. 2006, $12,366-372$.

(55) Schneidman-Duhovny, D.; Nussinov, R.; Wolfson, H. J. Front. Med. Chem. 2006, 3, 585-613.

(56) Hetényi, C.; Van Der Spoel, D. Protein Sci. 2002, 11, 1729-1737.

(57) Ewing, T. J. A.; Kuntz, I. D. J. Comput. Chem. 1997, 18, 11751189 .

(58) Case, D. A.; Darden, T. A.; Cheatham, T. E.; Simmerling, C. L. Wang, J.; Duke, R. E.; Luo, R.; Crowley, M.; Walker, R. C. W.; Zhang Merz, K. M.; Wang, B.; Hayik, S.; Roitberg, A.; Seabra, G.; Kolossváry, I.; Wong, K. F.; Paesani, F.; Vanicek, J.; Wu, X.; Brozell, S. R.;
Steinbrecher, T.; Gohlke, H.; Yang, L., Tan, C.; Mongan, J.; Hornak, V.; Cui, G.; Mathews, D. H.; Seetin, M. G.; Sagui, C.; Babin, V.; Kollman, P. A. AMBER; University of California: San Francisco, CA, 2008.

(59) Duan, Y.; Wu, C.; Chowdhury, S.; Lee, M. C.; Xiong, G.; Zhang, W.; Yang, R.; Cieplak, P.; Luo, R.; Lee, T.; Caldwell, J.; Wang, J.; Kollman, P. A. J. Comput. Chem. 2003, 24, 1999-2012.

(60) Onufriev, A.; Bashford, D.; Case, D. A. Proteins 2004, 55, $383-$ 394.

(61) Feig, M.; Onufriev, A.; Lee, M.; Im, W.; Case, D. A.; Brooks, C. L. J. Comput. Chem. 2004, 25, 265-284.

(62) Weiser, J.; Shenkin, P. S.; Still, W. C. J. Comput. Chem. 1999, 20 , $217-230$.

(63) Srinivasan, J.; Trevathan, M. W.; Beroza, P; Case, D. A. Theor Chem. Acc. 1999, 101, 426-434.

(64) Ryckaert, J. P.; Ciccotti, G.; Berendsen, H. J. C. J. Comput. Phys. 1977, 23, 327-341.

(65) Loncharich, R. J.; Brooks, B. R.; Pastor, R. W. Biopolymers 1992, $32,523-535$.

(66) Izaguirre, J. A.; Catarello, D. P.; Wozniak, J. M.; Skeel, R. D. J. Chem. Phys. 2001, 114, 2090-2098.

(67) Kollman, P. A.; Massova, I.; Reyes, C.; Kuhn, B.; Huo, S.; Chong, L.; Lee, M.; Lee, T.; Duan, Y.; Wang, W.; Donini, O.; Srivasan, J.; Case,

D. A.; Cheatam, T. E., III. Acc. Chem. Res. 2000, 33, 889-897.

(68) Sitkoff, D.; Sharp, K.; Honing, B. J. Phys. Chem. 1994, 98, 19781988.

(69) Pearlman, D. A. J. Med. Chem. 2005, 48, 7796-7807. 913

(70) Gohlke, H.; Kiel, C.; Case, D. A. J. Mol. Biol. 2003, 330, 891-

(71) Hubbard, S. J.; Thornton, J. M. 'NACCESS', Computer Program, Department of Biochemistry and Molecular Biology, University College London, 1993.

(72) Buša, J.; Džurina, J.; Hayryan, E.; Hayryan, S.; Hu, C. K.; Plavka, J.; Pokorný, I.; Skørivánek, J.; Wu, M. C. Comput. Phys. Commun. 2005, $165,59-96$.

(73) Sobolev, V.; Sorokine, A.; Prilusky, J.; Abola, E. E.; Edelman, M. Bioinformatics 1999, 15, 327-332.

(74) Heather, A. C.; McCammon, J. A. Mol. Pharmacol. 2000, 57, 213 218.

(75) McCammon, J. A. Biochim. Biophys. Acta 2005, 221-224.

(76) Bonnet, P.; Bryce, R. A. J. Mol. Graphics Modell. 2005, 24, 147156.

(77) Tsui, V.; Case, D. A. J. Am. Chem. Soc. 2000, 122, 2489-2498. (78) Xiong, B.; Huang, X. Q.; Shen, L. L.; Shen, J. H.; Luo, X. M.; Shen, X.; Jiang, H. L.; Chen, K. X. Acta Pharmacol. Sin. 2004, 6, 705713.

(79) Gorfe, A. A.; Caflisch, A. Structure 2005, 13, 1487-1498.

(80) Novotny, J.; Bruccoleri, R. E.; Bruccoleri, M.; Bruccoleri, K. A. J. Mol. Biol. 1997, 268, 401-411.

(81) Novotny, J.; Bruccoleri, R. E.; Davis, M.; Kim, A. Biophys. Chem. 1996, 61, 37-49.

(82) Miyamoto, S.; Kollman, P. A. Proc. Natl. Acad. Sci. U.S.A. 1993, 90, 8402-8406.

(83) Archakov, A. I.; Govorun, V. M.; Dubanov, A. V.; Ivanov, Y. D.; Veselovsky, A. V.; Lewi, P.; Janssen, P. Proteomics 2003, 3, 380-391.

(84) Williams, D. H.; Stephens, E.; O'Brien, D. P.; Zhou, M. Angew. Chem., Int. Ed. 2004, 43, 6596-6616.

(85) Brady, G. Curr. Opin. Struct. Biol. 1997, 7, 215-221.

(86) Lumry, R.; Rajender, S. Biopolymers 1970, 9, 1125-1227.

(87) Exner, O. Prog. Phys. Org. Chem. 1973, 10, 411-482.

(88) Cornish-Bowden, A. J. Biosci. 2002, 27, 121-126.

(89) Tsai, C. J.; Del Sol, A.; Nussinov, R. J. Mol. Biol. 2008, 378, 111.

(90) Tsai, C. J.; Del Sol, A.; Nussinov, R. BioSystems 2009, 5, 207216.

(91) Wang, J. P.; Morin, P.; Wang, W.; Kollman, P. A. J. Am. Chem. Soc. 2001, 123, 5221-5230.

(92) Lee, J.; Natarajan, M.; Nashine, V. C.; Socolich, M.; Vo, T.; Russ, W. P.; Benkovic, S. J.; Ranganathan, R. Science 2008, 322, 438-442.

(93) Levine, I. N. Physical Chemistry, 2nd ed.; McGraw-Hill Co.: New York, 1993; p 125.

JP104983A 